\title{
Microscopic Findings Evaluator
}

National Cancer Institute

\section{Source}

National Cancer Institute. Microscopic Findings Evaluator. NCI Thesaurus. Code C117598.

A person who determines the significance of a microscopic findings assessment. 